University of Wollongong

Research Online

Faculty of Engineering and Information

Faculty of Engineering and Information

Sciences - Papers: Part A

Sciences

2007

Editorial: special issue contributed from CHEMECA 2006-Australasian process modelling and control selected papers

Mark Nelson

University of Wollongong, mnelson@uow.edu.au

Brent Young

University of Auckland, b.young@auckland.ac.nz

Follow this and additional works at: https://ro.uow.edu.au/eispapers

Part of the Engineering Commons, and the Science and Technology Studies Commons

Research Online is the open access institutional repository for the University of Wollongong. For further information contact the UOW Library: research-pubs@uow.edu.au 


\title{
Editorial: special issue contributed from CHEMECA 2006-Australasian process modelling and control selected papers
}

\author{
Abstract \\ The papers in this issue of Chemical Product and Process Modelling are substantially those that arose \\ from special sessions on "process simulation and control" (organised by Brent R. Young) and \\ "mathematical modeling" (organised by Mark I. Nelson) at the 34th Australasian Chemical Engineering \\ Conference (held between 17-20th September 2006, in Auckland, New Zealand). The papers in this \\ special issue are available at: http://www.bepress.com/cppm/vol2/iss2. The papers featured in this issue \\ have been revised and extended from CHEMECA and re-reviewed before publication here.All the papers in \\ this issue use mathematics. However, this special issue only features a small number of the \\ presentations at CHEMECA that use mathematics. Mathematics finds many practical applications within \\ chemical engineering and consequently presentations involving mathematics were featured in many \\ special sessions throughout CHEMECA. Some of these presentations will appear in special issues \\ elsewhere. In particular, the papers from every session that were nominated for the John Brodie award \\ are appearing in a special issue of the Asian-Pacific Journal of Chemical Engineering.
}

\section{Keywords}

process, modelling, selected, papers, issue, chemeca, 2006, australasian, control, special, contributed, editorial

Disciplines

Engineering | Science and Technology Studies

\section{Publication Details}

Nelson, M. I. \& Young, B. R. (2007). Editorial: special issue contributed from CHEMECA 2006-Australasian process modelling and control selected papers. Chemical Product and Process Modeling, 2 (2), 1-4. 


\title{
Editorial: Special Issue Contributed from CHEMECA 2006-Australasian Process Modelling and Control Selected Papers
}

\author{
Mark I. Nelson and Brent R. Young
}

\begin{abstract}
The papers in this issue of Chemical Product and Process Modelling are substantially those that arose from special sessions on "process simulation and control" (organised by Brent R. Young) and "mathematical modeling" (organised by Mark I. Nelson) at the 34th Australasian Chemical Engineering Conference (held between 17-20th September 2006, in Auckland, New Zealand). The papers in this special issue are iss2. The papers featured in this issue have been revised and extended from CHEMECA and re-

reviewed before publication here.

All the papers in this issue use mathematics. However, this special issue only features a small number of the presentations at CHEMECA that use mathematics. Mathematics finds many practical applications within chemical engineering and consequently presentations involving mathematics were featured in many special sessions throughout CHEMECA. Some of these presentations will appear in special issues elsewhere. In particular, the papers from every session that were nominated for the John Brodie award are appearing in a special issue of the AsianPacific Journal of Chemical Engineering.

Author Notes: This special issue of Chemical Product and Process Modelling would have been impossible without the help of many people. The editors of this special issue thank the editors of Chemical Product and Process Modelling, who encouraged us throughout the process of organising this special issue, the anonymous referees, who provided their time and energy in the usual way, and, above all, the authors of the papers that appear in this issue. Guest Editors: Mark I. Nelson, School of Mathematics and Applied Statistics, University of Wollongong, Australia, and Brent R. Young, Department of Chemical \& Materials Engineering, University of Auckland, New Zealand.
\end{abstract}




\section{Summary of papers}

\section{Control}

Many chemical engineering processes consist of multi-unit operations in which the output from one operation is an input into a subsequent operation. A variety of techniques are available to control such processes, some of which apply only to steady-state operation whilst others can be used to achieve dynamic control. The distinction between dynamic control and steady-state control is useful in practice because, for example, dynamic models are often unavailable during process design whilst steady-state process models are commonly available.

The implementation of any control scheme requires the values of some of the process variables. The required values can often be measured on-line; however the measured values may differ from the 'true' values as a consequence of random or systematic measurement errors. Plant data are frequently dynamic and thus a dynamic data reconciliation approach is required to estimate the 'true' values of time dependent process variables. Effective processing of plant data to remove noise will lead to improvements in process control. Dynamic data reconciliation is the subject of the paper by Tellez-Schmill et al which uses a process simulator model to transform a constrained optimization problem into an unconstrained problem; the point being that the latter requires less computational effort than the former.

Santoso et al (1) investigate the process operability of a high-purity distillation column for methanol-water separation using the framework of steadystate attainability. To assess the static operability of the process it is assumed that the input variables, i.e. the initial conditions of the process model, can be varied over some range in parameter space. This defines a hyper-volume (A) in parameter space. The set of initial conditions within (A) that evolve to the desired steady-state defines a second hyper-volume (B). A new metric, the Output Controllability Index (OCI) is defined. To determine the $\mathrm{OCI}$ for a given steadystate solution a dynamic process simulator is required. It should be noted that this approach does not provide any information on the dynamic approach towards the required steady-state solution, thus the solution may evolve towards the desired steady-state solution along a path that is undesirable.

Santoso et al (2) present an easy-to-use approach, based upon the concept of passive systems, to estimate the dynamic controllability of multi-unit processes. The method is applied to three case studies: a heat integrated distillation column; a distillation column with a side-stream; and, a supercritical fluid extraction process. 


\section{Modelling}

A classic chemical engineering process is to use one unit to carry out a chemical reaction and a second unit to purify the desired products by distillation. The performance of this multi-unit operation can sometimes be improved by integrating the reaction and distillation steps in a single multifunctional process unit. Patel et al present a dynamic mathematical model for ethyl acetate synthesis using reactive batch distillation. This is an attractive process since removal of the product from the reaction mixture shifts the equilibrium in the forward direction, improving the conversion of the reactants. The authors find the optimum operating policy, i.e., reflux ratio and batch time, for a product purity of $50 \%$ ethyl acetate by dynamic simulation of the reactive distillation model.

Aluminium reduction cells operate at high temperatures and contain highly corrosive materials. It is therefore very difficult to obtain experimental data relating to the bath flow field caused by anode bubbles. Zhou et al use a two-phase turbulence model to analyse the movement and flow fields of the electrolyte induced by the anode gas around a single anode. It is assumed that the bath flow field is incompressible and operating at steady-state. This paper is a good illustration of the insights that can be obtained from simulation techniques when experimental approaches are impractical.

Fluid catalytic cracking (FCC) is an important refinery process which converts heavy petroleum fractions into highly valuable products such as gasoline. Good mixing between the solid catalyst and the fluid oil feed at the base of the FCC unit is essential to ensure complete feed vaporisation. Novia et al report the findings of a computational study of a FCC unit in which the hydrodynamics are simulated in three dimensions using a two-phase turbulence model. The reaction kinetics are represented by a lumped kinetic model containing three variables. Unlike many previous studies, idealised mixing conditions are not assumed within the riser reactor - mixing conditions are predicted by the computational fluid dynamics model. Their results show that most of the mixing phenomena occur in the first three to five meters of the riser reactor length.

Water drinking systems are required to deliver water to consumers at specified chlorine concentrations; chlorination being the most widely used method for water disinfection. Muslim et al model the chlorine concentration within a pipe using a linear advection-diffusion-reaction equation. The model is validated using literature data. The authors show how the model can be used to determine the locations at which chlorine should be injected into the water supply to maintain the chlorine concentration within the safe drinking water limits.

The frequent occurrence of fires at landfill sites motivates the work reported by Sidhu et al, who model self-heating in compost piles and at landfills. 
In such environments heat is generated at low temperatures by processes involving the growth and respiration of micro-organisms and at higher temperatures by the oxidation of cellulosic materials. The steady-state behaviour is investigated for two-dimensional slab geometries. Three stable solution branches are found: the lowest of which represents a state of negligible heatreaction; the middle branch is an elevated temperature branch, which is the feature of interest in composting facilities and municipal tips; the highest branch represents flaming combustion within the compost heap. Transition between these three types of behaviour are well defined by bifurcations.

Crude oil fouling of heat exchangers is an unavoidable operating problem at an oil refinery which leads to a reduction in the heat transfer coefficient of the crude preheat train. Zabiri et al apply principal component analysis to plant data to remove outliers and to identify the most important process variables. The resulting data is then used to develop a neural network model for the, time varying, efficiency of the heat transfer coefficient. The resulting model, which has a correlation coefficient, $R^{2}$ of approximately 0.98 , will be used to timetable the cleaning of the heat exchanger, which happens when the efficiency drops below $30 \%$, to minimise operational disruptions.

Hot pressing is one of the most important operations in medium density fibreboard manufacture. Dynamic interactions occur during pressing including heat transfer, moisture transfer, pressure development, internal stress changes, wood consolidation, resin curing, particle bonding and the development of a nonuniform density distribution through the board. A new mathematical model based on theoretical analysis and experimental information was developed by Gupta et al that can predict these interactions. The performance of the model was validated by experiments conducted in a pilot scale press.

\section{Papers []}

Gupta, A., Jordan, P.J., Pang, S., Modelling of the Development of the Vertical Density Profile of MDF during Hot Pressing.

Muslim, A., Li, Q., Tade, M.O. Simulation of free chlorine decay and adaptive chlorine dosing by discrete time-space model for drinking water distribution systems.

Novia, N., Ray, M.S., Pareek, V.K. Three-dimensional hydrodynamics and reaction kinetics analysis in FCC riser reactors. 
Chemical Product and Process Modeling, Vol. 2 [2007], Iss. 2, Art. 1

Patel, R., Singh, K., Pareek, V., Tade, M.O. Dynamic simulation of reactive batch distillation column for ethyl acetate synthesis.

Santoso, H., Rojas, O.J., Bao, J., and Lee, P.L. (a) Nonlinear process operability analysis based on steady-state simulation: $A$ case study.

Santoso, H., Bao, J., \& Lee, P.L. Passivity Based Dynamic Controllability Analysis for Multi-Unit Processes.

Sidhu, H.S., Nelson, M.I., Luangwilai, T., Chen, X.D. Mathematical modelling of the self-heating process in compost piles.

Tellez-Schmill, R., Svrcek, W.Y., Young, B.R. On-line dynamic data reconciliation incorporating dynamic simulation.

Zabiri, H., Radhakrishnan, V.R., Ramasamy, M., Wah, C.S., Do Thanh, V., Ramli, N.M. Development of heat exchanger fouling model and preventive maintenance diagnostic tool.

Zhou, N., Xue, Y., Chen, J.J.J., Taylor, M.P. Numerical simulation of electrolyte two-phase flow induced by anode bubbles in an aluminium reduction cell. 